\title{
Power electronic grid connection of PM synchronous generator for wind turbines
}

\author{
dr.ir. M. Van Dessel \\ DE NAYER Instituut - Dept. Industr. Wetensch. \\ J. De Nayerlaan 5 \\ B-2860 St. Katelijne Waver, Belgium \\ Michel.VanDessel@denayer.wenk.be
}

Abstract

This paper discusses the configuration and operation of a power electronic converter used for grid connection of a permanent magnet generator designed for variable speed wind turbines. Initially the test platform for permanent magnet generators is described, followed by the design parameters of the PM synchronous generator developed for wind turbines in the $10 \mathrm{~kW}$ range. For optimal grid connection of the generator, a topology of the power electronic converter has been chosen using an Active Front End mains rectifier supplying the DC link and Motion Control inverter connected to the generator. Finally the measurement results obtained from grid connection of the permanent magnet synchronous generator are presented followed by some conclusions.

\section{TEST PLATFORM FOR WIND TURBINE GENERATORS}

In the course of a research project focused on wind turbines in the $10 \mathrm{~kW}$ range a test platform for permanent magnet (PM) generators has been constructed including a power electronic converter for grid connection [1].

\author{
dr.ir. G. Deconinck \\ K.U. Leuven - ESAT / ELECTA \\ Kasteelpark Arenberg 10 \\ B-3001 Leuven, Belgium \\ Geert.Deconinck@esat.kuleuven.be
}

The test platform for PM synchronous generator is used both for research purposes as well as for educational purposes as part of the laboratory infrastructure for courses on power electronics and electrical drives for engineering students. Laboratory tests using the platform are part of a distributed course on intelligent electrical energy systems, developed by six institutes for higher engineering education in co-operation with the research group ELECTA of K.U. Leuven ESAT [2].

The machine side of the test platform as shown in fig. 1 consists of an electromechanical drive train for the permanent magnet wind turbine generator, driven by a frequency controlled asynchronous motor for variable speed operation. The single stage gearbox with ratio 1:3.59 converts the drive motor speed range 150 - $1500 \mathrm{rpm}$ into generator speed range $42-418 \mathrm{rpm}$. The torque sensor is mounted on the motor side shaft where torque is lowest so that it can be determined using an inductive measurement principle with $1 \%$ accuracy. The generator rotor position and speed are measured using an incremental encoder connected to the external drive shaft.

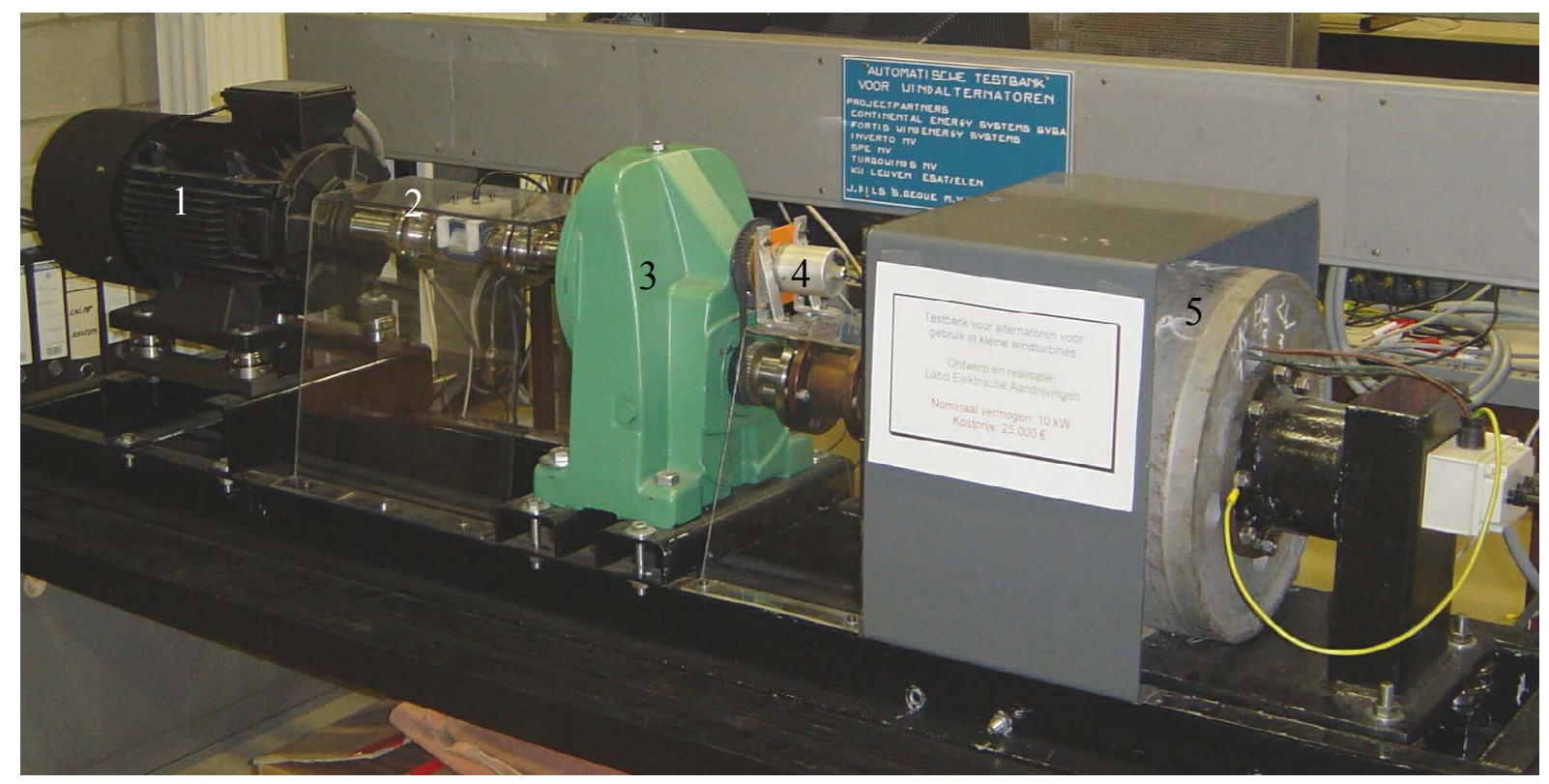

Fig. 1. Machine side of test platform for permanent magnet synchronous generator from $10 \mathrm{~kW}$ wind turbine.

1. Asynchronous motor $150-1500 \mathrm{rpm}$ with built in encoder for speed measurement

2. Inductive torque sensor with $1 \%$ measurement accuracy

3. Gearbox 1:3.59 for generator speed $42-418 \mathrm{rpm}$

4. Encoder for rotor position and speed measurement

5. Permanent magnet synchronous generator enclosed in safety cage 


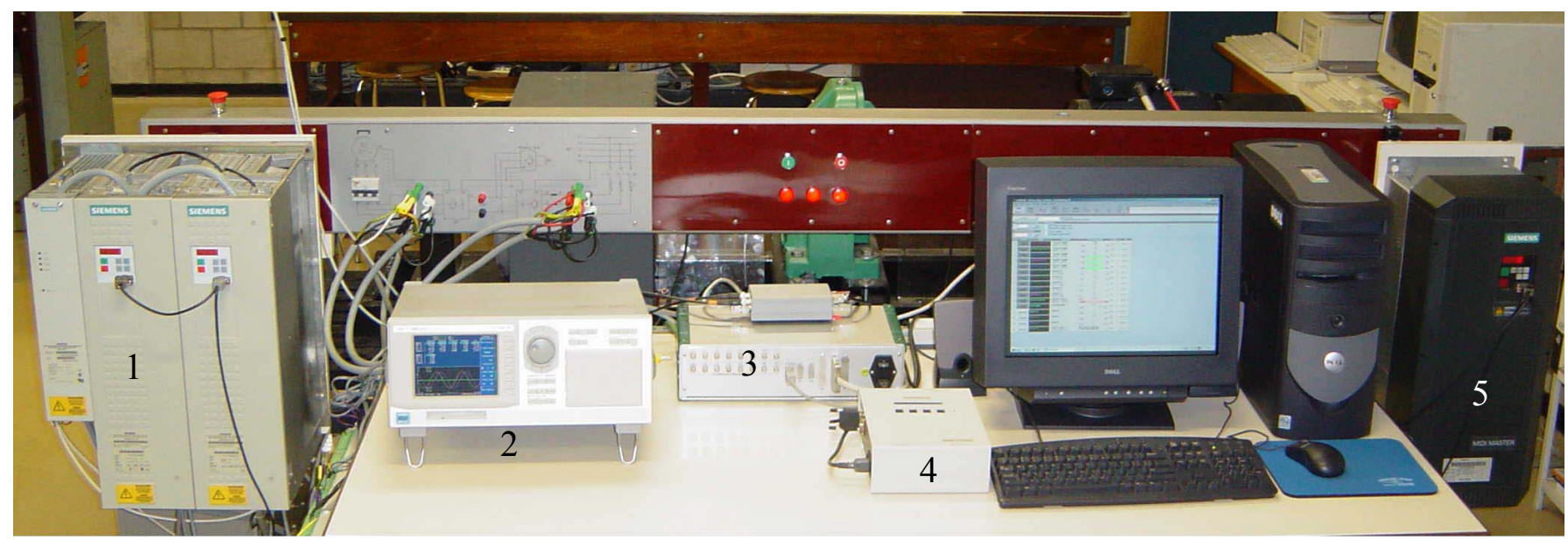

Fig. 2. Electronics side of test platform for permanent magnet synchronous generator including converter for grid connection.

1. Siemens Masterdrive power electronic converter (Active Front End supply unit and Motion Control inverter)

2. Power analyser Yokogawa WT1600

3. Dewetron data acquisition system

4. Wind speed simulator

5. Siemens frequency converter for variable speed control

Fig. 2 shows the electronics side of the test platform, consisting of following components:

- the power electronic converter used for grid connection of the PM synchronous generator;

- the power analyser for electric power measurement and calculation of generator and converter efficiency;

- the data acquisition system for registration of speed, torque, temperature, voltage and current measurements;

- the wind simulation system generating speed setpoints from wind speed measurement data;

- the frequency converter for variable speed control of the asynchronous motor drive.

\section{PM SYNCHRONOUS GENERATOR}

The PM synchronous generator mounted on the test platform is a prototype. Its electromagnetic design has been optimised for minimum harmonic content of induced voltage and maximum efficiency using finite element calculations [1].

This generator is built up from standard motor parts in a totally enclosed housing without cooling ribs and without fan and fan cover. The frame is made of steel Fe370 and is hot zinc dipped and coated. The magnetic field is supplied by $\mathrm{NdFeB}$ permanent magnets with radial magnetisation. They are mounted on a pole wheel directly driven by the wind turbine blades using an internal stationary stainless steel shaft with rotational speeds up to $350 \mathrm{rpm}$. The stator is built using standard stator sheets fitted with 54 slots. The windings having especially protected class $\mathrm{F}$ isolation are three phase star connected. By means of a specific stator winding design, magnetic bonding of the pole wheel is nearly eliminated, such that the starting torque depends effectively on bearing friction only. The rotation of the magnets induces a three phase AC voltage in the stator windings [3].

The main design parameters of the generator and wind turbine are given in tables 1 and 2.
TABLE 1

DESIGN PARAMETERS OF PM SYNCHRONOUS GENERATOR

\begin{tabular}{|l|l|}
\hline Generator type & Fortis Alize II \\
\hline Magnet material & $\mathrm{NdFeB}$ \\
\hline Active length & $140 \mathrm{~mm}$ \\
\hline Air gap width & $3.75 \mathrm{~mm}$ \\
\hline Nominal speed $\mathrm{n}$ & $300 \mathrm{rpm}$ \\
\hline Speed range & $25 \mathrm{rpm}-350 \mathrm{rpm}$ \\
\hline Nominal torque $\mathrm{T}_{\text {nom }}$ & $275 \mathrm{Nm}$ \\
\hline Maximal torque $\mathrm{T}_{\max }$ & $340 \mathrm{Nm}$ \\
\hline Nominal electrical power $\mathrm{P}_{\mathrm{e}, \text { nom }}$ & $7.4 \mathrm{~kW} @ 300 \mathrm{rpm}$ \\
\hline Maximal electrical power $\mathrm{P}_{\mathrm{e}, \text { max }}$ & $10.6 \mathrm{~kW} @ 350 \mathrm{rpm}$ \\
\hline Nominal line current $\mathrm{I}_{\mathrm{L}, \mathrm{nom}}$ & $15 \mathrm{~A}$ \\
\hline Maximal line current $\mathrm{I}_{\mathrm{L}, \max }$ & $20 \mathrm{~A}$ \\
\hline No-load voltage $\mathrm{U}_{\mathrm{L}}$ & $326 \mathrm{~V} \mathrm{@} 300 \mathrm{rpm}$ \\
\hline Number of pole pairs $\mathrm{p}$ & 6 \\
\hline Nominal frequency $\mathrm{f}$ & $30 \mathrm{~Hz}$ \\
\hline Phase resistance $\mathrm{R}_{\mathrm{s}}$ & $1.36 \mathrm{Ohm}$ \\
\hline Inductance (direct) $\mathrm{L}_{\mathrm{d}}$ & $12.5 \mathrm{mH}$ \\
\hline Inductance (quadrature) $\mathrm{L}_{\mathrm{q}}$ & $12.5 \mathrm{mH}$ \\
\hline
\end{tabular}

TABLE 2

SPECIFICATIONS OF FORTIS ALIZE WIND TURBINE

\begin{tabular}{|l|l|}
\hline Rotor type & 3 blade upwind with fixed pitch \\
\hline Blade material & fibre glass reinforced epoxy \\
\hline Blade length & $3.4 \mathrm{~m}$ \\
\hline Rotor diameter & $7.0 \mathrm{~m}$ \\
\hline Rotor area & $38.5 \mathrm{~m}^{2}$ \\
\hline Rotor speed & $25-350 \mathrm{rpm}$ \\
\hline Tip speed & max. $100 \mathrm{~m} / \mathrm{sec}$ \\
\hline Rated output & $10.0 \mathrm{~kW}$ \\
\hline
\end{tabular}




\section{CONVERTER FOR GRID CONNECTION}

The power electronic converter providing a grid interface for the PM synchronous generator consists of three main modules: the Active Front End (AFE) supply unit, the DC link bus with braking chopper, and the Motion Control inverter connected to the PM synchronous machine.

The AFE supply unit is basically a line commutated inverter, using an active rectifier bridge built from IGBT power switches (Insulated Gate Bipolar Transistor) as shown in fig. 3. Its 'Control Unit for Supply AFE' or CUSA control board is synchronised with the power grid $(400 \mathrm{~V}, 50 \mathrm{~Hz})$ by means of the Voltage Sensing Board (VSB). The precharging resistors $R_{v}$ limit the peak currents in the supply line that occur when switching on the IGBT bridge, which acts as a rectifier charging capacitors in the DC link bus. This type of converter is available in power ranges up to $250 \mathrm{~kW} \mathrm{[4].}$
Essential for the operation of the AFE are the reactors at the mains side connection (one in each supply line). They allow transfer of power from the grid to the DC bus and vice versa (regenerative mode). The AFE reactors also act as commutating reactors reducing harmonics and eliminating peak currents at current changeover between power switches and free wheeling diodes within the inverter.

The Motion Control inverter connects the PM synchronous machine to the DC link bus (fig. 4). It consists of a IGBT bridge inverter and a control electronics board (CUMC). The 'Control Unit Motion Control' uses vector control algorithms based upon measured rotor position to control the torque and speed of the synchronous permanent magnet machine (servomotor or generator as in this application). Setpoints and parameters are entered using the Parameterizing and Monitoring Unit (PMU) or the serial interface. Optional boards include the interface for the incremental encoder.

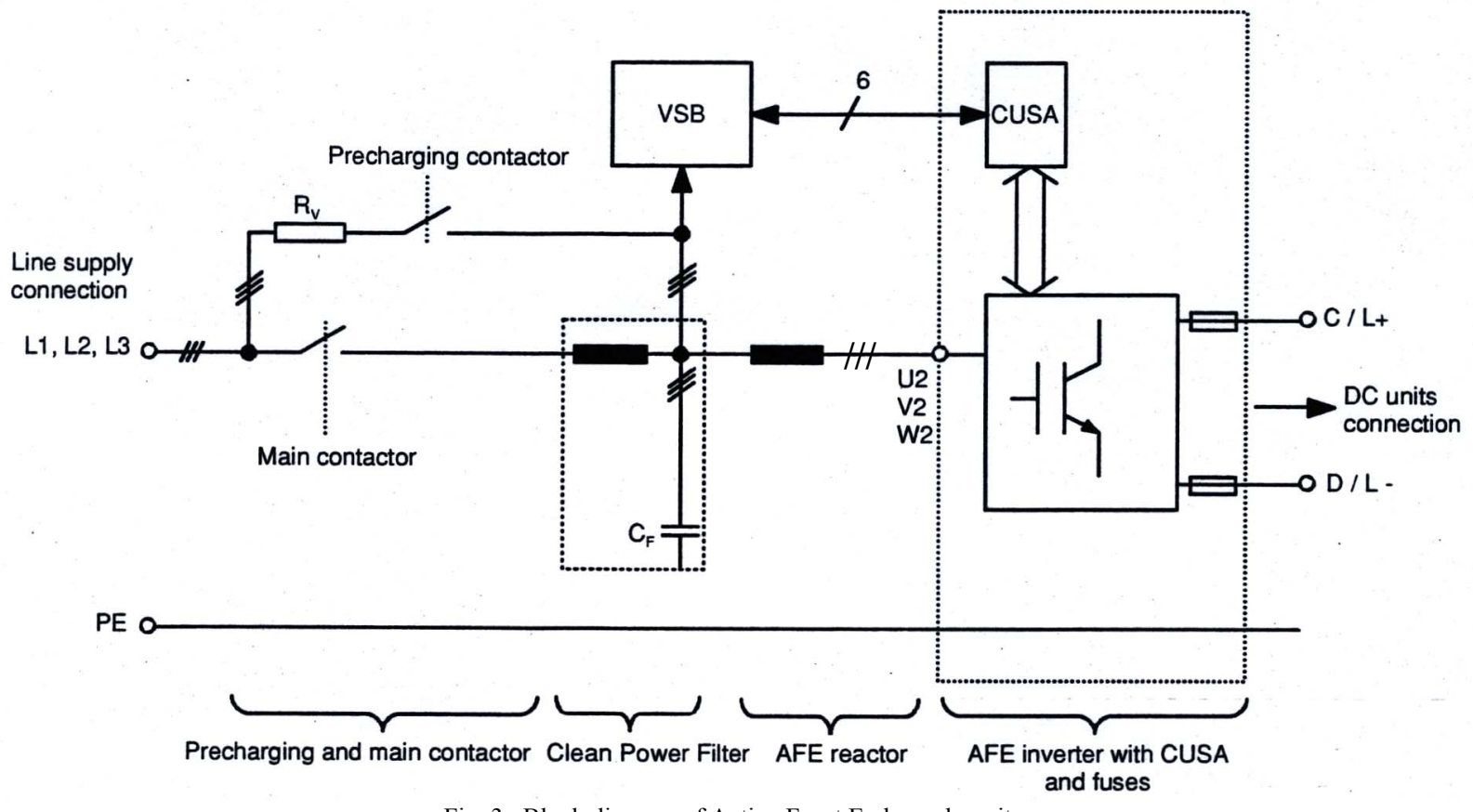

Fig. 3. Block diagram of Active Front End supply unit.

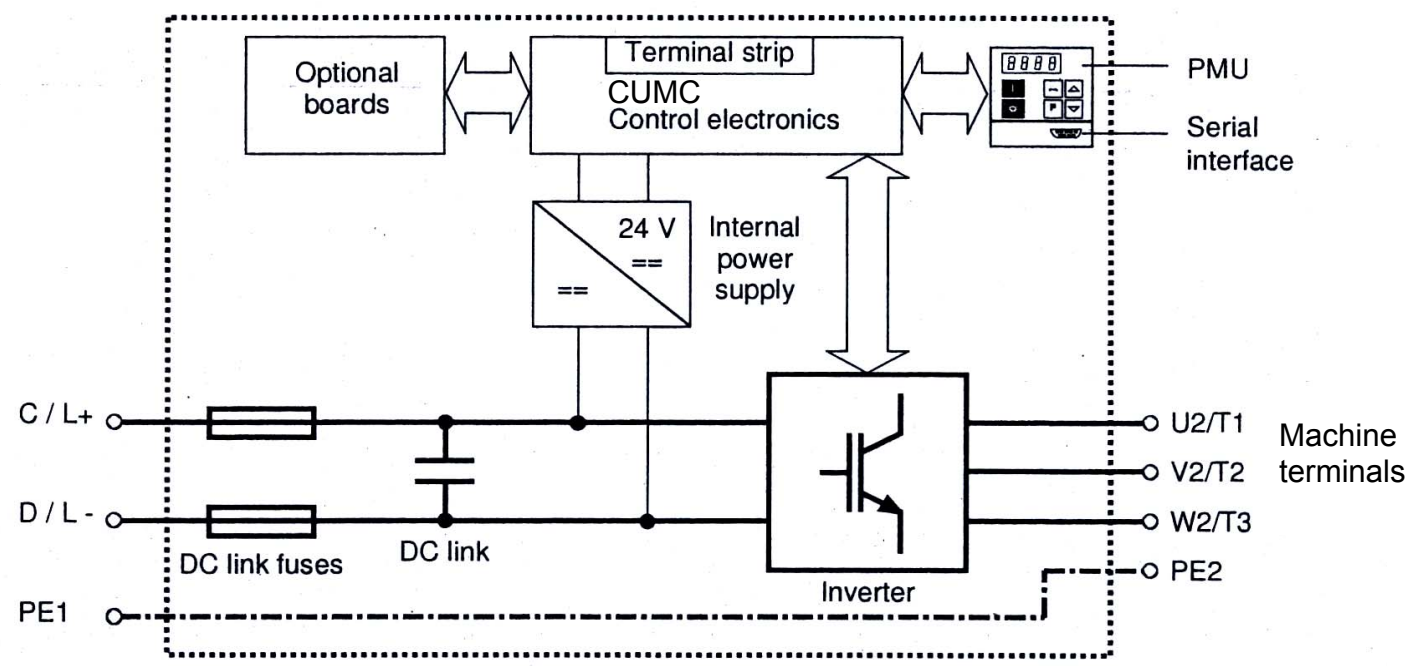

Fig. 4. Block diagram of Motion Control inverter. 


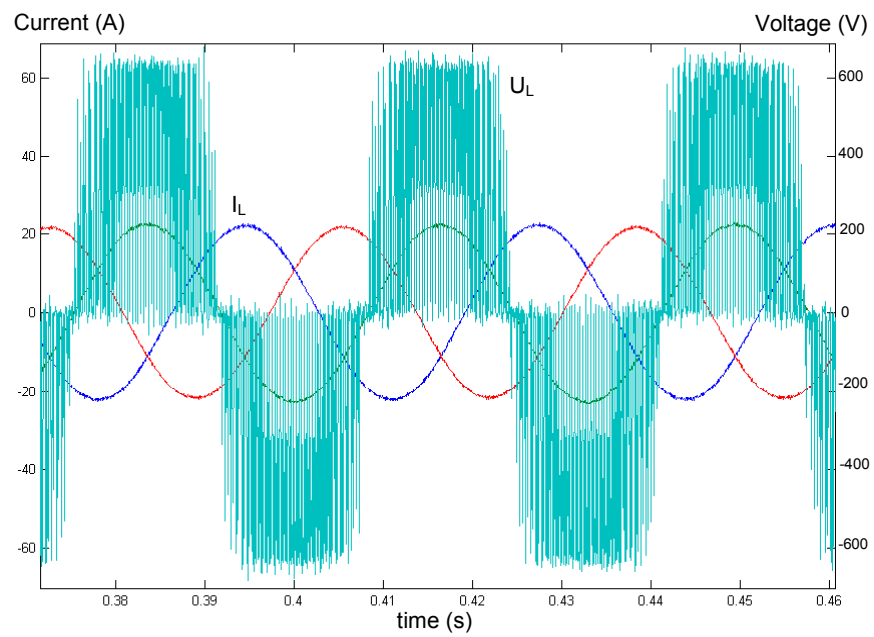

Fig. 5. Generator voltage and current with IGBT inverter.

The complete power electronic converter offers a suited grid connection of wind power: controllable current to regulate the rotor torque, low harmonic distortion compared with a diode rectifier and smoothed power injection. Using this type of line commutated converter it is possible to feed the power into the grid at $50 \mathrm{~Hz}$ and $400 \mathrm{~V}$, whatever the output frequency and voltage of the PM synchronous generator, depending on its variable speed [5]. Fig. 5 shows that by using an IGBT inverter on the generator side, currents are sinusoidal as a consequence of applying a line voltage generated using Pulse Width Modulation at $8 \mathrm{kHz}$, which isn't the case when a diode rectifier is applied.

Fig. 6. shows the step response of the torque control loop of the Motion Control inverter used for the PM generator as measured by the data acquisition system. To obtain such a fast torque response with controlled overshoot, the parameters in the vector control block diagram have been optimised using the machine identification procedure of the Motion Control inverter which provides auto tuning of parameters [4]. For control strategy purpose, the inverter is programmed to load the PM generator in order to obtain maximum power from the wind. This is achieved by controlling the torque proportional to the square of the speed [6].

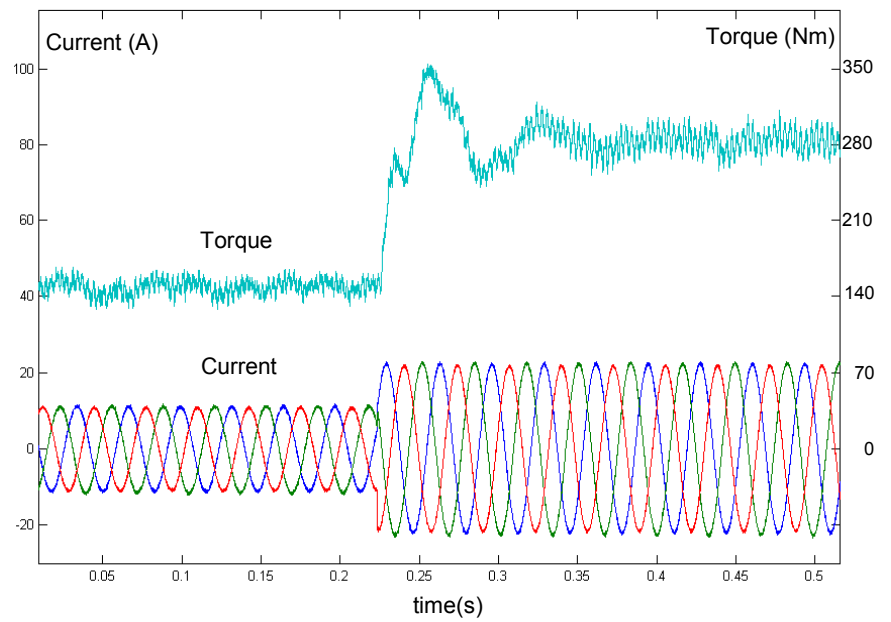

Fig. 6. Step response of torque control loop of Motion Control inverter.

\section{MEASUREMENT RESULTS FOR THE GRID CONNECTION}

In this section the measurement results for the grid connection of the permanent magnet synchronous generator using the power electronic converter and test platform described above are presented. Using measured values for speed (n, unit $\mathrm{rpm})$ and torque $(\mathrm{T}$, unit $\mathrm{Nm})$ from the data acquisition system, the mechanical input power $\mathrm{P}_{\mathrm{m}}$ is calculated online using the motor evaluation function of the power analyser [7], which implements the equation:

$$
P_{m}=T \cdot\left(\frac{2 \cdot \pi \cdot n}{60}\right) .
$$

The generator electrical power $\mathrm{P}_{\mathrm{e}}$ is calculated by the power analyser using the 'two-wattmeter' measurement method and divided by the mechanical input power $\mathrm{P}_{\mathrm{m}}$ to obtain the generator efficiency $\eta_{\mathrm{g}}$.

$$
\eta_{g}=\frac{P_{e}}{P_{m}}=\frac{P_{U W}+P_{V W}}{P_{m}}
$$

The generator efficiency $\eta_{\mathrm{g}}$ is plotted as a function of rotational speed in fig. 7. It reaches values of $85 \%$ at nominal load and speed. The parameter for the curves is the setpoint for electromagnetic torque $\mathrm{T}_{\mathrm{em}}$, varying from $25 \%$ to $125 \%$ of nominal torque. All curves show an increase in efficiency with increasing speed. In the $T_{e m}$ range $120 \mathrm{Nm}$ to $300 \mathrm{Nm}$ a lower loading of the generator leads to higher efficiency for the same speed. The curve with $\mathrm{T}_{\mathrm{em}}=60 \mathrm{Nm}$ is an exception because at $25 \%$ load, efficiency is dominated by mechanical losses.

The electrical power at the mains side of the converter $\mathrm{P}_{\text {grid }}$ is calculated by the power analyser using the 'two-wattmeter' measurement method and divided by the generator electrical power $P_{e}$ to obtain the converter efficiency $\eta_{\text {conv }}$.

$$
\eta_{\text {conv }}=\frac{P_{\text {grid }}}{P_{e}}=\frac{P_{13}+P_{23}}{P_{e}}
$$

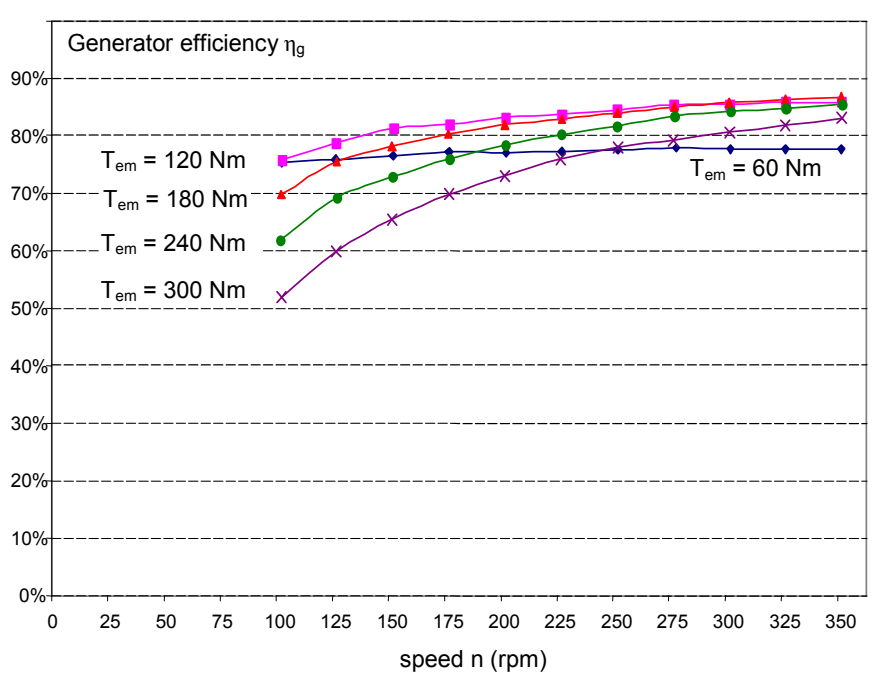

Fig. 7. Generator efficiency $\eta_{g}$ as a function of speed $n$. 
Converter efficiency $\eta_{\text {conv }}$

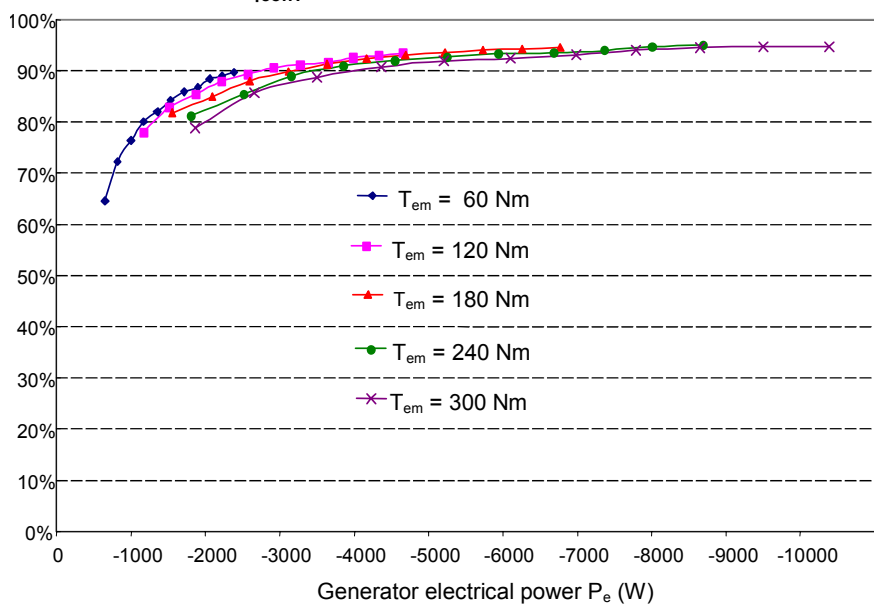

Fig. 8. Converter efficiency $\eta_{\text {conv }}$ as a function of generator electrical power.

The converter efficiency $\eta_{\text {conv }}$ is plotted as a function of generator electrical power $\mathrm{P}_{\mathrm{e}}$ in fig. 8. For values of $\mathrm{P}_{\mathrm{e}}$ in excess of $-3000 \mathrm{~W}$ the efficiency is more than $85 \%$, and stays above $90 \%$ for values of $\mathrm{P}_{\mathrm{e}}$ of more than $-4000 \mathrm{~W}$. The electrical power is negative due to the chosen machine reference system where consumed power is treated positive sign, delivered power negative.

The total efficiency $\eta$ for the grid connection of the permanent magnet synchronous generator is calculated as the ratio of the electrical power delivered to the grid $\mathrm{P}_{\text {grid }}$ to the mechanical input power $\mathrm{P}_{\mathrm{m}}$ :

$$
\eta=\frac{P_{\text {grid }}}{P_{m}}
$$

The total efficiency $\eta$ of grid connected generator as a function of rotational speed $n$ measured on the test platform for different values of the electromagnetic torque setpoint is depicted in fig. 9. For lower speeds and thus lower electrical output of the generator, the total efficiency is significantly lower than for generator only due to low converter efficiency.

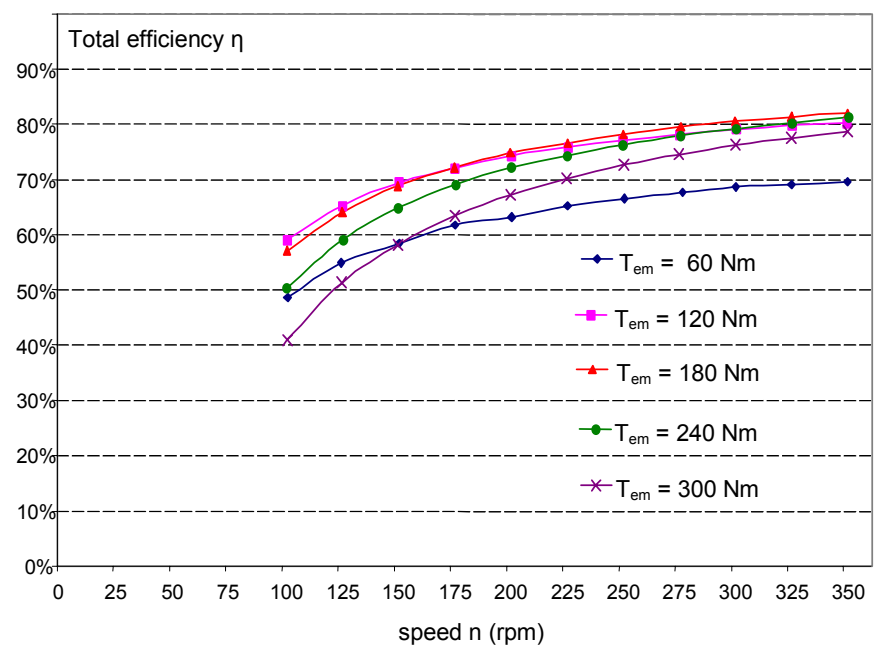

Fig. 9. Total efficiency $\eta$ of grid connected generator as a function of speed.

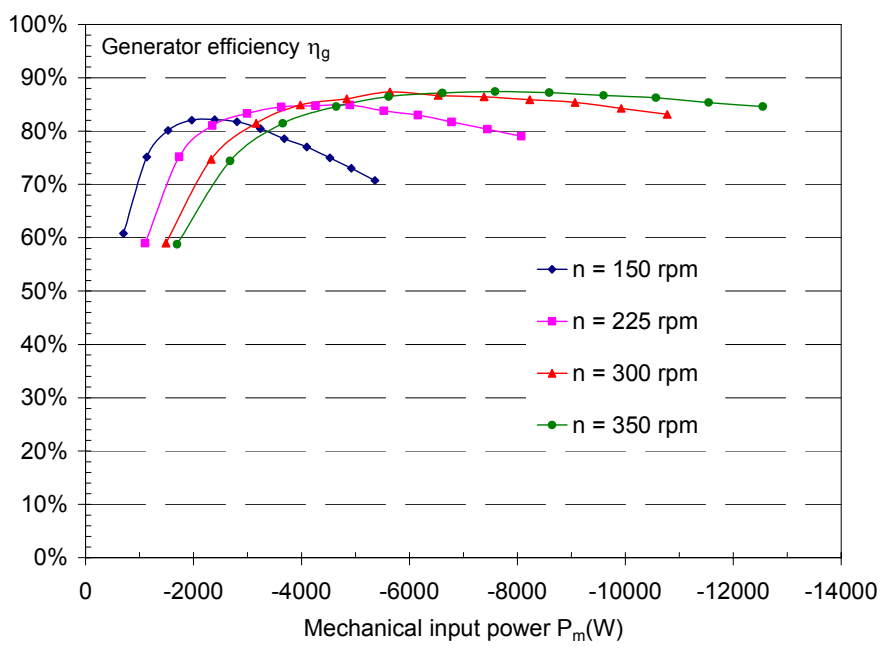

Fig. 10. Generator efficiency $\eta_{\mathrm{g}}$ as a function of mechanical input power.

In another set of measurements the generator speed is kept constant and used as a plot parameter rather than the torque setpoint as in previous graphs. The generator efficiency $\eta_{\mathrm{g}}$ given by (2) is plotted in fig. 10 as a function of mechanical input power $\mathrm{P}_{\mathrm{m}}$ at constant rotational speed $\mathrm{n}$. Each curve has a maximum value depending on mechanical input power $\mathrm{P}_{\mathrm{m}}$. The curve maximum increases and shifts towards the right with increasing speed $n$. The generator efficiency reaches a maximum value of $87,4 \%$ at maximal speed of $350 \mathrm{rpm}$.

The generator power factor is defined as:

$$
\lambda=\frac{P_{e}}{\sqrt{3} \cdot U_{L} \cdot I_{L}},
$$

where $\mathrm{U}_{\mathrm{L}}$ and $\mathrm{I}_{\mathrm{L}}$ are RMS line voltage and RMS line current, averaged on measurement of two line values. It is plotted in fig. 11 as a function of generator electrical power $\mathrm{P}_{\mathrm{e}}$. The absolute value of the power factor increases with increasing speed and thus higher generated line voltage. At any given constant speed the absolute value of the power factor reaches a maximum value for relatively small generated power and further decreases for larger electrical power output, especially at lower speeds where the difference in power factor is $20 \%$.

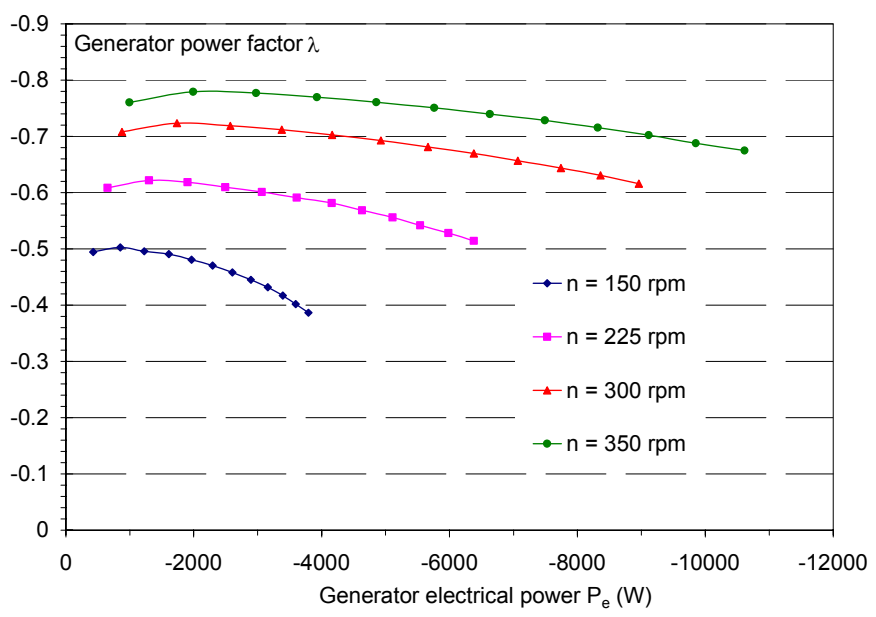

Fig. 11. Generator power factor as a function of generator electrical power. 


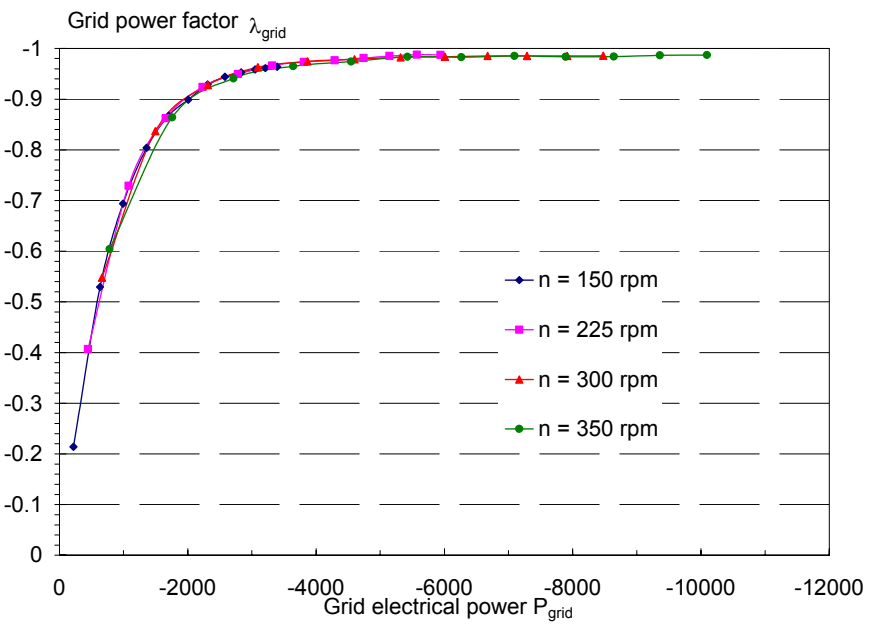

Fig. 12. Grid power factor as a function of grid electrical power.

The grid power factor is defined as:

$$
\lambda_{\text {grid }}=\frac{P_{\text {grid }}}{\sqrt{3} \cdot U_{L, \text { grid }} \cdot I_{L, \text { grid }}},
$$

where $\mathrm{U}_{\mathrm{L} \text {,grid }}$ and $\mathrm{I}_{\mathrm{L} \text {,grid }}$ are RMS line voltage and RMS line current at the mains side of the converter, averaged on measurement of two line values. It is plotted in fig. 12 as a function of electrical power $\mathrm{P}_{\text {grid }}$ delivered to the grid. Since the grid power factor is controlled by the Active Front End of the power electronic converter, it is only dependent on the amount of power delivered to the grid and not on generator speed and generated voltage. For values of $\mathrm{P}_{\text {grid }}$ in excess of $-3000 \mathrm{~W}$ the power factor is -0.95 or higher. Comparing the figs. 11 and 12 clearly shows the advantage of using the power electronic converter in two stages: the Motion Control inverter on the machine side and the Active Front End at the mains side allow different power factors.

The total efficiency $\eta$ of the grid connected generator as a function of mechanical input power for different values of the rotational speed $n$ is depicted in fig. 13. For mechanical input power less than $-3000 \mathrm{~W}$ and thus low electrical output of the generator, the total efficiency is significantly lower than for generator only due to lower converter efficiency (fig. 8).

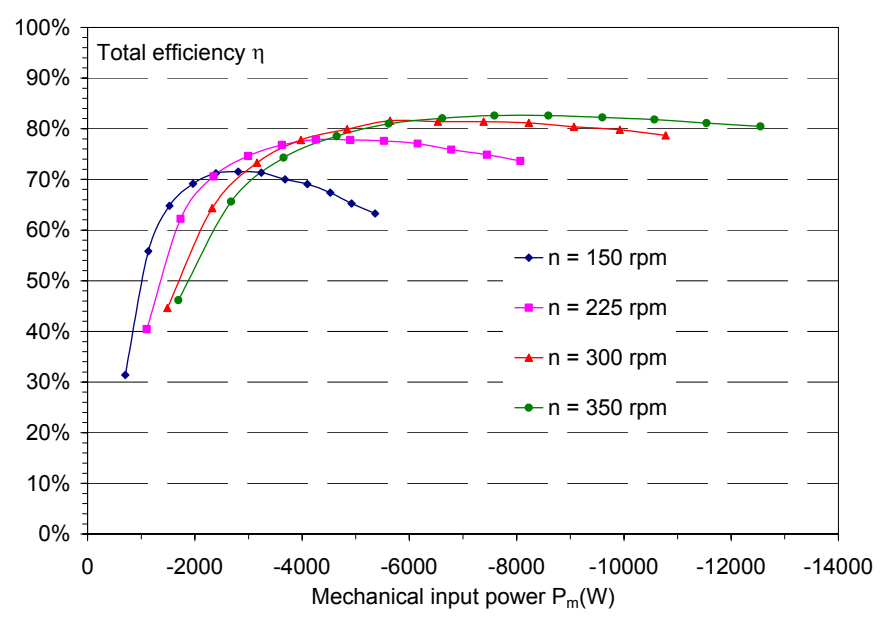

Fig. 13. Total efficiency $\eta$ as a function of mechanical input power.

\section{CONCLUSIONS}

This paper describes the configuration and operation of a power electronic converter used for grid connection of a permanent magnet generator developed for variable speed wind turbines in the range $10 \mathrm{~kW}-40 \mathrm{~kW}$. For optimal grid connection a topology of the power electronic converter has been chosen using an Active Front End mains rectifier supplying the DC link and Motion Controlled inverter loading the generator. In this way it is possible to feed the generated power into the grid at $50 \mathrm{~Hz}$ and $400 \mathrm{~V}$, whatever the output frequency and voltage of the generator, depending on its variable speed. The power factor at the mains side of the converter is independent of the generator power factor. The fact that a power electronic converter initially developed for industrial drives can be engineered to efficiently couple a specifically developed PM synchronous generator to the grid makes the original result. This type of converter is available in power ranges up to $250 \mathrm{~kW}$ and can be used for PM synchronous and asynchronous machines. The test platform including its advanced measurement equipment is one of the few reported in literature regarding development of permanent magnet wind turbine generators. Results for the grid connection of the synchronous generator using the power electronic converter and test platform include the efficiency curves for the generator, for the converter and total efficiency defined as the ratio of the electrical power delivered to the grid to mechanical input power.

\section{ACKNOWLEDGMENT}

The authors wish to thank the Flemish Institute for innovation through scientific research and technology (IWT) for its funding of the research project HOBU 010159 enabling the realisation of the work described in the paper. They also thank the 'Associatie K.U. Leuven' for its financial support in the project OOF 2003/15 setting up the distributed course on intelligent electrical energy systems.

\section{REFERENCES}

[1] S. Bequé, J. Dils, M. Van Dessel, "Optimisation of a direct drive low speed permanent magnet wind generator", Proceedings of the Nordic Matlab Conference 2003, Copenhagen, Denmark, 21 - 22 Oct. 2003, pp. 215 - 219.

[2] G. Deconinck, "Developing a Distributed Hands-On Course for Teaching Advanced Electrical Engineering Topics", Int. Journal of Electrical Engineering Education (IJEEE) (Manchester University Press), Vol. 44, No.1, Jan. 2007, pp. 1-11.

[3] Fortis Wind Energy Systems, "Wind turbine technical specifications", www.fortiswindenergy.co.uk/index.asp?id=38.

[4] Siemens Automation and Drives Catalogue DA 65/11 "Simovert Masterdrives Motion Control", 'Engineering information' pp. 6/36-6/65, 2003/2004.

[5] J. Svensson, "Grid-connected Voltage Source Converter - Control Principles and Wind Energy Applications", Technical Report No. 331, Chalmers University of Technology, Göteborg, Sweden, March 1998.

[6] E. Muljadi, K. Pierce, P. Migliore, "Control strategy for variable-speed stall-regulated wind turbines", National Renewable Energy Laboratory, American Control Conference 1998, Philadelphia, Pennsylvania, June 28-30, 1998.

[7] Yokogawa Electric Corporation, "WT1600 Digital Power Meter user's manual", IM760101-01E, $4^{\text {th }}$ edition 2004. 